\title{
PIpetron Tunnel Construction Issues
}

\author{
James E. Friant \\ Colorado School of Mines and Excavation Engineering Associates, Inc., 1352 SW 175 th St., \\ Seattle, WA 98166 \\ Robert A. Bauer and David L. Gross \\ Illinois State Geological Survey, 615 East Peabody Drive, Champaign, IL 61820 \\ Michael May and Joseph Lach \\ Fermi National Accelerator Laboratory, P. O. Box 500, Batavia, IL 60510
}

\section{INTRODUCTION}

This report examines issues involved in the civil construction aspects of the tunneling that could be done in the region of Ferriliab to support the Pipetron - a long. moderately deep, iunnel loop. Cost, technical and political aspects of tunneling are addressed in this preliminary guide for further stucy.

At Snowmass 96, in a series of informal, but comprehensive discussions, several guidelines were developed to frame this report.

a. The location of the Pipetron would be at least partially within the existing property of Fermilab, a site that permits the tunnel to be placed in generally competent dolomite/limesione, whose rock characteristics are already wall known.

b. Cost will be compelling factor. Politically, it will be impossible to secure funding uniess the project is perceived to produce good physics at a bargain price.

c. Public perception will be immensely important. Minimal surface disturbances, land use, noise, vibration, and environmental impact are significant considerations.

d. Since construction would stan no sooner than 10 years hence, this report should consider technological advances in tunneling probable in that time frame. In addition, a reasonable amount of tunneling research and development is assumed to be asseciated with the Pipetron project.

\section{ISSUES}

Prior to discussion of potential drilling or boring methods for the tunnel, the discussion group at Snowmass 96 identifled as important characteristics of any tunneling system:

a. Penetration ra:e

b. Uilization rate and machine availability

c. Accuracy, the a'sility to steer precisely

d. The ability to line and 0 or water proof the tunnel

s. The need for maintenance of the tunneling system

1. Surtace disturbance, number of shatts

g. Muck handling

h. Power distribution

1. Status of technology; $R$ \& $D$ needs
For this report, the minimum finished tunnel diameter considered is $1.22 \mathrm{~m}$ and the maximum sizs considered is that found to be cheapest by contractors.

\section{TUNNELING METHODS}

Five tunnel excevation methods may be of interest. In the text that follows, each is described with respect to the issues listed in section II.

\section{A. Directional Drilling}

Dlrectional drilling is a method used for placing utility pipes under itvers or other surface inaccessible areas. It is a muiti-step process which features a guided pilot hole. There are different guidance systems for cutting through soil versus rock. Steering mechanisms are not available in large drill bit sizes. Therefore, after the pilot bit "holes through, ${ }^{n}$ if the finished hole is to be larger than about 23 $\mathrm{cm}$, a reamer is attached to the pipe. The reamer can be attached to either end of the pipe and it is pulled/cut through the ground, guided by the pilot hole, until it breaks through. By definition, this method requires access from both ends of the intended alignment.

Penetration Rate - In rock, the penetration rate is very slow; under $3 \mathrm{~m}$ per hour. Back reaming is also alow because thrust and torque are limited to the strength of the drill pipe or pulling mechanism. Overall construction time is long because, in addition to slow penetration, it is a multi-step process.

Utilization Rate - When things are working well, utilization rate is high. The downtime is mainly adding or removing pipe sections. However, when things do not go well, down times can be counted in weeks or even ronths. Retrieving a broken off cutting head in the hole may often cause the hole to be abandoned.

Accuracy - Accuracy of the final hole is dictated by the pilot hole. Accuracy of the pilot hole is only possible by trequent survaying. Near-surface holes, within 9 to $15 \mathrm{~m}$ of the ground surface, can use subsurface detection devices almost continuously. For deep precision drilling, a survay must be run frequently. This means stopping dinilling as often as every $6 \mathrm{~m}$ so a reading can be taken (MWDMeasure While Drilling). This has eliminated the need to "trip" (pull out) the bit. Horizontal MWD tools are an even more recent ( 2 or 3 years) innovation.

Lining and Sealing - In small hole sizes, liners are 
sometimes pulled or pushed into the hole just behind the reamer. Often, however, this constituies a third steo. A steel liner is pulled or pushed into the hole in sections. Sections are welded together prior to insertion.

Maintenance. The thrust and sometimes rotary power are located in the stanting shaft and can be sasily maintained. Maintenance cannot be accomplished on the in-hole components. One only plans on going trom exposure point to exposure point; from shaft to shaft, or surface to surface. In-hole mishaps are cured by pulling the device out, or drilling a small shaft (2 911 hole) to retrieve orilling equipment, or by abandenment of the hole.

Surface Disturbence - A vertical shaft, larger than the diameter of the horizontal tunnel would be needed at 300 to $600 \mathrm{~m}$ intervals with today's technology.

Muck Handling - Muck removal is commonly by slurry. In a few large rock holes that have been bored using a horizontal raise drill, cuttings have been simply washed out with copious amounts of water. The most practical in the Pipetron case would be to pump a siumy to the surface and use a separation system.

Power Supoly - This method is a rather low power demand system. Frequently, the set up includes a generating unit. Power in-hole, to the cutting tool, is mechanically or hydraulically supplied from outside.

Status of Technology - To make the method practical for the Pipetron, some break-through dovelopments are needed. Deep cover guidance, longer lasting cutting tools, more efficient rock cuttings, one pass operation for $1.22 \mathrm{~m}$ minimum holes, and most importantly, an order of magnitude increase in length between shafts would be needed to make this method practical for Pipetron construction use.

\section{B. Standard Micro-tunneling}

Micro-funneling is a process of excavating a small diameter (under $1.83 \mathrm{~m}$ ) tunnel while simukaneously installing a liner. The general term for the operation is "pipe jacking." As the name inters, thrust to the machine outterhead is provided by large hydraulic cylinders lecated in a shaft, at the same depth as the tunnel alignment. The cylinders exert pressure on each section of pipe (frequently $3.05 \mathrm{~m}$ long) as each section is, in turn, shoved into the hole. Boring proceeds in a sequential manner, with the machine inoperable as new seetions of pipe are added at the jacking station in the shaft.

The length of a bore, with jacking pressure only from the shatt, is perhaps $450 \mathrm{~m}$ between shafts; slightly less in soft ground, slightly more in more competent formations. This length can be extended by the use of intermediate jacking stations. These unirs, placed at intervals of perhaps 210 to $305 \mathrm{~m}$ can extend the useful length of the system to about $900 \mathrm{~m}$ between shafts. Al the end of the drive, the intermediate jacking stations are stripped of their hydraulies and the telescoping shell is permanently sealed by welding or epoxy. Construction workers enter the tunnel for thls operation. Micro-tunnaling in solid rock has taken plece only within the last two years.
Peneiration Rate - Penetration rate on current systems is limited by the slurry removal system. A 40 horse power (hp), $1.247 \mathrm{~m}$ diameter unit achieved $6.7 \mathrm{~m} / \mathrm{hr}$ and a $40 \mathrm{hp}$, $0.810 \mathrm{~m}$ diameter unit achieved $12.2 \mathrm{~m} / \mathrm{hr}$; both in sandstone. Penetration potential with adequate mucking is about $30.5 \mathrm{~m} / \mathrm{hr}$. Rates over $36.6 \mathrm{~m} / \mathrm{hr}$ have been demonstrated in the laboratory with a 4.83 m cutterhead.

Utilization Rate - Utilization rates in excess of $30 \%$ are rare. With current technology, it lakes longer to add a pipe section than to bore.

Accuracy - All small bore micro-tunneling to dats has been straight, guided by laser beam. The machines are capable of 360 degrese continuous alignment correction. Maintaining accuracy within $2.5 \mathrm{~cm}$ at $300 \mathrm{~m}$ is common. In larger diameters, where pipe jacking has included a large radius curve, a more complex, manned entry guidance system is necessary. Accuracy is still within 2.5 $\mathrm{cm}$.

Llaing and Sealing - Boring and lining is a one-step process. Therefore, when the Micro-tunneler reaches the next shatt, the hole is completely liried. Steel, glasspolyester, conerete and clay pipe are commercially available.

Maintenance - Little in-the-hole maintenance is possible. The machine must be pulled or "rescued" by means of a shaft ( 911 hole). It cannot be backed out of the hole without removal of the pipe (liner). Bope lengths are selected based on anticipated machine encurance.

Surface Disturbance. A large diameter shaft for the jacking station is needed at $1.8 \mathrm{~km}$ intervals, and a smaller retrieval shaft' is needed between each entry shaft.

Muck Handling - Mucking is by slurry, in iimestone/dolomite, water can be used as the mucking fluid and separation of rock cuttings from the water is relatively easy.

Power Supply - This is a low power draw system; 80 hp for a $1.22 \mathrm{~m}$ diameter hole and 400 hp for a $3.05 \mathrm{~m}$ diameter hole are adequate.

Status of Technology. The system, until recently, has been confined to soils and soft rock. Commercial lechnology is advancing rapidly and the oapability of effective boring in very hard pock has now been demonstrated.

\section{Enhanced Micro-tunneling}

Enhanced micre-tunneling, now in early stages of commercialization, is similar to micro-tunneling, but seeks to eliminate micro-tunnaling weak points. It could, perhaps, be defined as a cross between micro-tunneling and a Tunnel Boring Machine (TBM).

In enhanced micro-tunneling the mucking system is dry, or altemately, could be made pumpable at the machine by the addition of about $15 \%$ by weight water (as opposed to a slurry which is $90.95 \%$ by weight water or mud). Thrust is provided by a gripping system on the machine which eliminates the need for the large jacking system. Lining can be jacked into the hole as a second step, or in largor diameters, lining can be placed in 
segments behind the machine. The Enhanced Microtunneling system is designed for a size range of about 1.22 to $3.05 \mathrm{~m}$ diameter.

Penetration Rate - The one prototype desion in the field has had painfully slow penetration rates because archalc cutter technology is being used. A $3.05 \mathrm{~m}$ unit (military project) demonstrated $24.4 \mathrm{~m} / \mathrm{hr}$, and laboratory demonstrations of over $36.6 / \mathrm{hr}$ penetration rates on a 1.83 $m$ unit have been accomplished.

Utllization Rate - No meaningful utilization rates have been demonstrated, but since operation is virtually identical to a modem TEM setup, rates of 50 to $60 \%$ could be expected.

Accuracy - The system is continuously steered, laser guided; accuracy is precise. Larger units are manned; small units are remotely controlled.

Lining and Sealing - This can be accomplished either simultaneously with boring or as a second step. In larger diameters, segment placing is well established. in smaller diameters, casing and grouting methods are well established. In any size, automated spraying systems for shotcrete or p:astic are well established.

Maintenance - In smaller size units, in-the-hole maintenance is limited. However, units could be designed to extract the machinerystor repair and access to the cutter head. Larger units are designed so that virtually overy component can be repaired, replaced, or maintained. Maintenance becomes a non-criteria issue for establishing tunnel reach lengths.

Surface Disturbance - A practical distance between access shafts would be about $6,100 \mathrm{~m}$. Smaller diameter power drop/escapolair-water drop shafts at $3,050 \mathrm{~m}$ intervals would be practical.

Muck Handling - The most probable system to employ, so that the mucking system does not pace the machine, is a conveyor belt. For example, if a $2.74 \mathrm{~m}$ dlamster machine is excavating at a rate of $15.2 \mathrm{~m} / \mathrm{hr}$, th produces $213,000 \mathrm{~kg}$ per hour of rock. This would require a $61 \mathrm{~cm}$ wide beit, running at full speed. Both pneumatic and concrete pump slurry might be considered but belt is the most likely candidate.

Power Supply - Since this is a low power draw system, power taken from a commercial grid would be tolerable. A $1.22 \mathrm{~m}$ machine may require about $80 \mathrm{hp}$, a $3.05 \mathrm{~m}$ machine, 500 hp maximum. Another $200 \mathrm{hp}$ for the belt mucking syatem may be required. If a pneumatic system is used, to extract $180,000+\mathrm{kg}$ per hour, soms $3,000 \mathrm{hp}$ would be necessary. Power draw and noise are serious issues with a pneumatic system.

Status of Technology - All the elements of a system are in place and have been demonstrated. One unit in the field has used poor technology and as a result has probably hindered system acceptance rather than heiped.

Some small TBM urits set up recently, did better. New advance records were set in April 1996 on a $4.27 \mathrm{~m}$ TaM with belt backup system. On the River Mt. Project (Nevada), a TBM bored $6.4 \mathrm{~km}$ of tunnel in 4 months and achieved a $140 \mathrm{~m}$ jay, and a $792 \mathrm{~m}$ week. It used no intermediate access points.

Small R \& D effots to develop a system in the 1.22 to
3.05 m diameter size range would almost certainly be successiul.

\section{Small, 1.83 to $3.05 \mathrm{~m}$ TBMS}

Tunnel Boring Machines are a highly developed, current excavating method for long tunneis. They are powerful machines, heavy, full face (the entire face of the cunnel is attacked simultaneously), and are operated in the tunnel by 6 to 12 persons or more.

Single rotating disc cutters are a proven cutting tool and are the exclusive tool of choice in rock tunnels. The full face rotating cutterhead is also equipped with buckets or sccops and functions as the primary muck pick-up system. As the cutterhead rotates, buckets move to the top of the tunnel and load a conveyor. Very successful machines of this basic conflguration have been built from 2.44 to 12.2 $m$ in diameter, and have worked in rock formations from massive and dry to soft, fractured and saturated; even under sea with as little as $15 \mathrm{~m}$ of cover.

TBMs are mostly electrically powered with a few hydraulic powered, and all develop their own thrust capability with hydraulic cylinders within the machine. In competent rock, large grippers fasten the machine to the tunnel wall to provide thrust and torque reaction.

The most common dise cutter sizes are from 43 to 48 $\mathrm{cm}$ diameter and require up to $27,000 \mathrm{~kg}$ of thrust each to penetrate hard rock.

Tunnel Borng Machines have not been extensively used in tunnels of less than $2.44 \mathrm{~m}$ in diameter. In fact, if a $2.44 \mathrm{~m}$ tunnel were required today, contraclors would likely bid using a 3.66 to $4.27 \mathrm{~m}$ diameter TBM.

Penetration Rate - Record penetration rates for smaller TBMs (less than $4.57 \mathrm{~m}$ in diameter) are about 8.1 $m$ per hour.

Utilization Fate - The record is $62 \%$ in the Chicago area dolomite/limestone. Rates of 40 to $50 \%$ ape considered very good. Since TBMs cperate in a regrio-bore sequence, an inherent downtime of about $20 \%$ exists to allow for resetting grippers. As penetration rate increases, the regrip time becomes a larger proportion of total time and utilization time drops. Constant boring schemes have been attempted by two manufacturers to eliminate this inherent downtime. However, noither attempt has been successful enough to gain universal acceptance.

Accuracy - Since these units are laser guided, and have 360 degrees of steering treedom. They can bs held to tolerances of only a few inches from true alignment over distances of several miles.

Lining and Sealing - The TBM system is capable of installing water tight linings of several types, concurrent with the boing process. In poor ground, where there is danger of water entry, sealed conorete segments have become the method of choice. In broken ground. steel sets and wire mesh lagging are installed under the TBM shielding. Rock bolting, shotcrete, straps, panning; virtually any type of roof support or lining requirements can be installed continuously or on an as needed basis by an open TBM system. No lining or sealing would be required for 
tunneling through the dolomites under Fermilab.

Maintenance - Vir.ually every functional part of a TBM sysiem can be maintained, repaired, or replaced in the tunnel. Even main bearings are peplaced (may take 4 months) in the tunnel. Regular maintenance shitts for lubricat:cn, service extension and cutting tool inspection are scheduled on a daily basis. Constant maintenance is key to highly successtul performance.

Surface Disturbance - Large access shafts for people and material access, as well as mucking and utilities, aro needed at perhaps $9,100 \mathrm{~m}$ intervals. Conscientious satety considerations may dictate an escape shaft of $611076 \mathrm{~cm}$ diameter at least half way in betwoen.

Muck Handling - Convoyor belts are the proven best current system. Conveyor systems, including vertical conveyors, have emerged as the system of choice within the past 5 years. Rail haulage is still popular, partialty because of the vast amount of used equipment available.

Power Supoly - Power costs are a substantial cost pep foot of iunnel. In remote areas, not blessed with a heary commercial grid, special power lines must be laid. Sometimes, the job must generate its own electricity, or accep: power cutoffs during peak draw hours. In the area contemplated for the Fipetron, obtaining the necessary electrical power would not be difficult.

Status of Technology - TBM systems and methods are totally developed and accepted. The lowest cost tunnel size at this time is about $4.27 \mathrm{~m}$ in diameter. Costs go up both as sizes get bigger and smaller from this point. The technology is available to move this "most economical" point to a smaller diameter of about 2.44 to $3.05 \mathrm{~m}$. With relatively small amounts of development work, the best features of small TBMs and large micro-tunnel machines could be combined.

\section{E. Retractable or Passing TBM}

The primany, and most predictable, maintenance item on any boring or drilling machine is the cutter replacement. A system which can roplace culters or even the full cutter head from within a small tunnel would extend the potential tunnel reach, or distance between access shafts.

A number of concepts were contemplated, and the most feasible is discussed here. The small machine would be based on a JARVA design TBM. The chassis of a JARVA machine is essentially a tubular beam, supported fore and aft by a set of grippers. A drive shaft runs through the tubular beam. The drive motors are located at the rear and the cutterhead is attached to the forward end of the ditue shałt.

In the replaceable hoad concept, the cutterhead is designed as a four am umbrella, with a permanent $46 \mathrm{~cm}$ inner dismeter. To withdraw the cutterhead, the maehine is backed up a short distance, the head is moved forward, collapsed and then pulled back. The entire eutterhead and drive staft are removec as a unit by being pulled out of the center tubular miain beam. A new or refurbished assembly is installed. Since these assemblies are only $46 \mathrm{~cm}$ in diameter, the two assemblies can pass in the tunnel. Some clever robotics would have to be designed for extraction, re-entry and for passing the units in the tunnel.

There is some design precedence for an expandable head, from $46 \mathrm{~cm}$ io as much as 1.83 \$0 $2.44 \mathrm{~m}$. At least two expandable reamers have boen built and field tested from which data and experience are available. Also, for a special purpose mining device, a head which expands from $46 \mathrm{~cm}$ to $1.83 \mathrm{~m}$ has been designed.

In the small size tunnels, the method would heve the potential of increasing the distance between access points. On the negative side, the same penetration rates as a solid head with cutters periectly placed, cannot be expected.

Also, on smaller sizes, the device for extracting and inserting the head would be large and likely prevent use of a conveyor as a primary muek pemoval systam. A concrete-like slurry and a positive displacement pump may bo a better answer, In the largest sizes, the belt may be possible.

Penetration Rate - Penetration rate of the retracting head TBM is not likely to be as great as the equivalent size Enhanced Micro-tunneler or the small TBM. This assumes that the expanding head would not be as stiff as a solid head design. Further, where a conveyor mucking system cannot be used, the mueking system may limit penetration rate.

Utilization Rate - Utilization rate may suffer somewhat compared with other methods because of the complexity of the machine and complexity involved in exchanging hoads. On the other hand, utilization rato cempared with Micro-tunneling or directional drilling methods would likely be better. Thus, this method would be most useful it it is dotermined that small tunnel size has precedence over cost. It improves penetration rate, utilization and length of a reach in smaller tunnel sizes.

Accuracy - The type of machine contemplated here steers in a different mods than the small TBM or micro. tunneling units discussed oarlier. Whereas the latter methods steer while boring, the double gripper JARVA design TBM steers during the gripper reset. During the boring stroke, it bores dead straight. In sharp tum radii, this series of short chords can be noticed on the tunnel wall. In the Pipetron application, because of the large radius, the chords would be virtually undetectable. Overall accuracy is comparable with the best methods, accuracy within a few inches.

Lining and Sealing. This method is no different than Enhanced Micro-tunneling of Small TBN methods. In any diameter, lining methods are well established.

Maintenance - The machine design is totally new, or a new concept, and employs many more moving parts than a conventional machine. In its early yesers of commereial use, high maintenance costs, design modifications and operating changes should be expected. In the longer term, the concept allows the most predictable wear item, cutters, to be changed while in tha hole. There are no automated cutter changing methods available today. Attempts to automate individual cutter changing have failed to date.

Surtace Disturbance. This methed falls in between the other methods; it would be an improvement over directional dpilling mathods and conventional slurry miero-sunneling, 
but would not be as good as Enhanced Micro-tunneling or a Small TEM for many years. Eventually, reliability may approach the better established methods and tunnel reach length could be improved.

Muck Handling - This aspect of the machine is viewed as complicated. Space is at a premium in small bore tunnels. It is hard to visualize how a relatively large, high capacity belt conveyor beit would lit into the smaller size tunnels with the requirement to transport large volumes of - muck, and pass the folded cutter head assemblies in the tunnel. Therefore, all but the largest tunnel sizes considered, say over $3.05 \mathrm{~m}$ diameter, would likely use some type of heavy slurry system. As mentioned earlier, muck removal could well pace the penstration rate.

Fower Supoly. This is a low power draw systern. Total power consumed over a given length of tunnel would be higher than the most efficient methods considered in this study. This is because penetration is somewhat slower, and in all but the largest tunnel diameters, cuttings would have to be sized to be compatible with a slurry pump. This raises the specific energy of excavation.

Status of Technolooy - While many components required for the retractable head TBM exist, this design concept has a new and complex arrangement. Development costs would be high, and success is not certain. Further, a few years of struggling with bugs and making design improvements both in the machine and in the extrection and transport systems would be expected.

In addition, every system of concept has competition, and the basic objectives should not be ignored. If the objective is to keep a tunneling machine in the ground for longar distances, other approaches should be compared. As an example, is the probabillty of success higher by focusing on an ultra long life cutter that does not need to be changed? Or could the same objective be accomplished by developing such a high speed tunneling machine that in the life span of a cutter, the machine creales more length of hole?

\section{SUMMARY AND CONCLUSIONS}

The most interesting result of this study was the observation that the technological dirsetion of at least three of the five excavation methods (enhanced micro-tunneling, small TBM's, and retractable or passing TBME) are similar. This conclusion is further explained by the following specific conclusions.

a. Mothods using a drill string to provide the excavating power in the hole have limited penetration rates and limited length between access points. This is because power to the face is limited, euttings size must be small and handling the drill string segments in a confined space (a shaft) is inefficient. Directional drilling is not the best choice for the Pipetron.

b. Methods employing pipe jacking are not good for the Pipetron, primarily because of the relatively short linear distance between access points required. Handling pipe segments is also difficult and time consuming in the shaft environment. Utilization rate suffers and lining costs are unnecessarily high.

c. The only muck removal system which has a chance to keep up with the improvements in excavation rates is a conveyor belt. Slurry systems, pneumatics or haulage containers of any sort, have major problems.

d. The smallest diameter hole of interest for the Pipetron project $(1.22 \mathrm{~m})$ is not likely to be the least costly. Currently, the least cost tunnel at the depth of the Pipetron is in the range of 3.66 to $4.27 \mathrm{~m}$ in diameter.

e. Building a system which depends entirely upon remcte control and robotics, a total non-human entry system, is not the most productive approach. A reasonably automated system, but one which allows a logical step-by-step development toward a total remote opsration, and one which in emergency cases, can sately employ human entry, is the best approach.

f. Since the geologic conditions at Fermilab are well studied and consistent, a cutting head can be designed for optimum efficiency in the specific rock tyce. This implies a wide cutting tool spacing which will form larger chunks rather than spoil similar to sand or gravel. This fact also discourages the use of a slumy system where spoil size may have to be sized for the pump capability.

With an eyolution in micro-tunneling toward larger diameters and dry systems for removal of muck, and with continual improvements in TBM technology, several opportunities exist for further advances in the lechnologies needed for the Pipetron.

a. Automated steering, power, and thrust control. A system available now has been tried on one TBM with semi-success.

b. Automated cutter changing; or cutters whlch don' need to be changed.

c. Cutters which can be placed at optimum positions without physical limitations.

d. Continuous boring to eliminate the regrip cycle. To date, commercial attempts have not been too successful.

e. Better instrumentation to detect imminent component failure, and coneurrently, automated and more effective general maintenance. The potential here is to eliminate the maintenance shitt, and to change talling parts, beiore they cause consequential damage.

f. Automated conveyor belt support structure installation.

g. Faster or even "on the fly" belt section addition.

The successful development of a few of these teatures makes the objectives of an under $\$ 1,000$ per $m$ tunnel reasonable. At the same time, it pushes the lowest cost tunnel size down to perhaps the 2.44 to $3.05 \mathrm{~m}$ range, improves environmental concerns, reduces surface disturbance (fewer or smaller shafts), and enhances satety. 